Research Paper

\title{
Serum Adiponectin Level May be an Independent Predictor of Clear Cell Renal Cell Carcinoma
}

\author{
Hongkai Wang ${ }^{1,2^{*}}$, Junlong $\mathrm{Wu}^{1,2^{*}}$, Weijie $\mathrm{Gu}^{1,2}$, Beihe Wang ${ }^{1,2}$, Fangning Wan ${ }^{1,2}$, Bo Dai ${ }^{1,2}$, Hailiang \\ Zhang ${ }^{1,2}$, Guohai Shi ${ }^{1,2}$, Yijun Shen ${ }^{1,2}$, Yiping Zhu ${ }^{1,2}$, Yao Zhu ${ }^{1,2^{*}}$, Dingwei Ye ${ }^{1,2}$ \\ 1. Department of Urology, Fudan University Shanghai Cancer Center, Shanghai 200032, China; \\ 2. Department of Oncology, Shanghai Medical College, Fudan University, Shanghai China. \\ *These authors contributed equally to this work. \\ $\bowtie$ Corresponding author: DingWei Ye, M.D. and Yao Zhu, M.D. Tel: 86-21-64175590-2807 Fax: 86-21-64434556 Email: dwyeli@163.com
}

( ) Ivyspring International Publisher. Reproduction is permitted for personal, noncommercial use, provided that the article is in whole, unmodified, and properly cited. See http://ivyspring.com/terms for terms and conditions.

Received: 2015.12.16; Accepted: 2016.05.24; Published: 2016.06.27

\begin{abstract}
Objectives: To examine whether serum adiponectin or leptin level has the ability to differentiate clear cell renal cell carcinoma (ccRCC) from other subtypes of renal cell carcinoma (RCC) in a Chinese population.

Patients and methods: We recruited 198 consecutive patients who were treated with radical or partial nephrectomy in our department from September 2011 to June 2013. Their histological types were all malignant, including clear cell, papillary, chromophobe and unclassified RCC. We also enrolled 86 people with no cancer or cancer-related diseases as normal controls. We measured patients' preoperative blood samples for plasma adiponectin and leptin concentrations using an enzyme-linked immunosorbent assay method. Statistical methods were used to analyze ccRCC and other subtypes as they relate to serum adiponectin/leptin level and other factors such as body mass index or visceral fat area.

Results: In our database, normal controls had significantly higher circulating adiponectin $(p<0.001)$ and leptin levels $(p<0.001)$ than patients with RCC. Among the 198 RCC patients, 156 patients had ccRCC while 42 patients had other histological types. Serum adiponectin levels were lower in ccRCC patients than in non-clear-cell RCC patients $(p=0.004)$. However, the plasma leptin level was not differently distributed between $c c R C C$ and non-ccRCC patients $(p=0.940)$. In multivariate analysis, we found that serum adiponectin level may be an independent predictor for discriminating $C \mathrm{R} C \mathrm{C}$ patients from others $(p=0.004)$. Furthermore, in the $c C R C C$ subgroup, we observed that men with $c c R C C$ had lower leptin $(p<0.001)$ and adiponectin $(p=0.002)$ levels, and diabetic patients had lower plasma adiponectin levels $(p=0.001)$.

Conclusions: Lower plasma adiponectin concentration was related to an increased incidence of ccRCC and may act as an independent predictor for ccRCC. Our study may help define the process from obesity to adipose tissue, to cytokines and finally to ccRCC.
\end{abstract}

Key words: Renal cell carcinoma (RCC), pathology, adiponectin, leptin.

\section{Introduction}

Renal cell carcinoma (RCC) is one of the most common malignant tumors. The incidence of RCC is rising gradually, both in the United States and China. It is estimated that there will be 61560 new cases of kidney and renal pelvis cancer in the United Sates in 2015 [1]. Over the last 10 years, many basic and clinical studies have demonstrated that RCC is one of a subset of cancers related to obesity and adipose tissue [2]. High body mass index (BMI) is associated with a higher risk of developing RCC [3]; however, patients with a higher BMI have a relatively longer overall survival, cancer-specific survival and recurrence-free survival [4]. The authors of these articles pointed out that obesity-related factors may be 
promising in understanding RCC and may have some translational application potential. In our previous study, we found that in the Chinese population, visceral fat accumulation (VFA) was mainly observed in clear cell renal cell carcinoma (ccRCC) patients but not in non-ccRCC patients [5]. However, the mechanism behind this phenomenon remains unknown.

Adiponectin is a $30-\mathrm{kD}$ protein secreted by white adipose tissue (WAT). The adiponectin concentration in plasma can reach up to $2-10 \mu \mathrm{g} / \mathrm{ml}$ in humans [6]. This means it can be easily detected, and it has a potential use in diagnosis or prognostication in some diseases, including RCC. Apart from adiponectin, adipose tissue also produces a variety of inflammation-related factors, including leptin, tumor necrosis factor- $\alpha$ (TNF- $\alpha$ ) and interleukin-6 (IL-6).

Several studies focusing on the relationship between RCC and adiponectin or other obesity-related factors have come to some preliminary conclusions. Pinthus et al. found that lower plasma adiponectin levels are associated with larger tumor size and metastasis in ccRCC[7]. Chou et al. suggested the adiponectin receptor 1 (AdipoR1) was more ubiquitously expressed in RCC tissues [8]. Some scientists verified the inverse association of leptin levels with RCC [9], and others confirmed that the relationship between serum leptin level and RCC may differ by ethnicity [10]. These studies indicate that adiponectin or leptin may play an important role in the interlinkage between obesity and RCC.

In this study, we examined whether adiponectin, leptin and VFA have some correlation with subtypes, grades, or pathological status of RCC, and we explored the "obesity-WAT-adiponectin/leptin-RCC" chain in defining different subtypes of RCC for further research use and translational applications.

\section{Methods}

\section{Patients}

We recruited consecutive patients who underwent radical or partial nephrectomy in our department from September 2011 to June 2013. The patients were all adults ( $>18$ years) diagnosed with malignant renal tumors. We excluded patients whose abdominal computed tomography images were not available and those whose pathological results had not been confirmed. Because of cachexia, we also excluded patients with metastatic renal tumors. Then we excluded patients with clinical characteristics that we were concerned about but which were incomplete. After testing the serum adiponectin level and leptin level, we excluded patients whose adiponectin concentration or leptin concentration was in the highest $5 \%$ or lowest $5 \%$ among all the patients, because these extreme data are usually due to measurement errors. Finally, 198 patients met our criteria and they all signed written informed consent forms to participate in the study. Additionally, we also enrolled 86 people who had no cancer or cancer-related diseases as normal controls. We collected their blood and tested their serum adiponectin and leptin levels.

Histological subtypes of malignant RCC included clear-cell, papillary, chromophobe and unclassified RCC, according to the 2004 World Health Organization classification of renal tumors [11]. Each slide was retrieved and examined by two experienced genitourinary pathologists blinded to the patient's clinical details.

We measured body weight $(\mathrm{kg})$ and height $(\mathrm{m})$ at the same time, and the BMI was calculated as the weight in kilograms divided by the height in square meters. The definitions and calculation of total fat area (TFA), subcutaneous fat area (SFA) and visceral fat area (VFA) were the same as described in our previously published article [5].

\section{Measurement of plasma adiponectin and leptin}

We collected patients' blood samples in the morning and after separation stored these samples at $-80^{\circ} \mathrm{C}$ until they were analyzed. We use an enzyme-linked immunosorbent assay (ELISA) kit (ab108786, Abcam, Cambridge, USA), which is specific for human adiponectin, to detect the level of adiponectin in patients' plasma according to the manufacturers' instructions. Each sample was detected in triplicate. Inter-assay precision was tested and found to be greater than $95 \%$. The detection of plasma leptin concentration was the same as that described above, using a human-specific leptin ELISA kit (EK1972, Multisciences, Shanghai, China).

\section{Statistical analysis}

Sex, smoking status, grades of ccRCC (Fuhrman I and II vs Fuhrman III and IV), hypertension, diabetes, BMI $<27$ vs $\geq 27 \mathrm{~kg} / \mathrm{m}^{2}$ for men and $<25$ and $\geq 25$ $\mathrm{kg} / \mathrm{m}^{2}$ for women (the threshold points for obesity in Asia) [12] were considered to be binary variables and presented as proportions. In patients with malignant RCC, pathological subtypes were checked to determine the presence of ccRCC or other types. Age, tumor size, the concentration of serum adiponectin and leptin, VFA, SFA, TFA and VFA\% (VFA/TFA $\times$ $100 \%)$ were counted as continuous variables and reported in the form of a median (range).

We used linear regression analysis to explore if the serum levels of adiponectin or leptin were linearly 
correlated with VFA. Unconditional logistic regression models were developed to find any relationship between age, sex, smoking status, hypertension, diabetes, serum levels of adiponectin and leptin, VFA, BMI or pathology (ccRCC or other). We used both univariate and multivariate analysis. Continuous data were compared with Student's $t$ test when the data matched the criteria of normal distribution and are presented as mean \pm standard deviation (SD) in the graphs. Because the serum level of adiponectin was not distributed normally, we used a nonparametric test (Mann-Whitney U) for comparison. All tests were two-sided and $\mathrm{p}$ values less than 0.05 were considered statistically significant. We used SPSS statistic software, version 19.0 (SPSS Inc., Chicago, IL, USA) to analyze the data.

\section{Results}

In total, 284 people participated in our study, including 198 RCC patients and 86 normal controls. The patient demographic and clinical characteristics are summarized and presented in Table 1. In the RCC patients' group, the median age was 54 years old and men accounted for $70.7 \%$. One hundred fifty-six patients $(78.8 \%)$ had ccRCC and 42 patients had other subtypes of RCC, including four with papillary $(2.0 \%), 28$ with chromophobe $(14.1 \%)$ and 10 with unclassified RCC (5.1\%). The mean BMI was 24.31 $\mathrm{kg} / \mathrm{m}^{2}$ and the mean VFA was $100.32 \mathrm{~cm}^{2}$. The mean serum adiponectin, leptin level and VFA of different histological types of RCC are shown in Fig. 1.

In the normal control group, the median age was 56 years old and men accounted for $69.8 \%$. The mean BMI of cancer-null patients is $24.23 \mathrm{~kg} / \mathrm{m}^{2}$ in this database. There was no significant difference between the RCC patients' group and normal controls' group in sex, age and BMI. However, cancer-null patients had significantly higher circulating adiponectin and leptin levels than RCC patients $(p<0.001)$, just as previously reported by other research teams $[9,13]$.

We then examined whether there were significant differences between ccRCC patients and non-ccRCC patients in the aspects of VFA or serum levels of leptin and adiponectin. We observed lower adiponectin levels in patients with ccRCC (median, $6.01 \mu \mathrm{g} / \mathrm{ml}$; SD \pm 3.94$)$ compared with patients with non-ccRCC (median, $8.11 \mu \mathrm{g} / \mathrm{ml}$; SD \pm 4.97 ), a statistically significant difference $(\mathrm{p}=0.004)$ (Fig. 2a, Table 2$)$. Significantly greater VFA $(p=0.042)$ was also observed in ccRCC patients (median, $107.79 \mathrm{~cm}^{2}$; $\mathrm{SD} \pm 44.63$ ) than in non-ccRCC patients (median, 78.85 $\mathrm{cm}^{2}$; $\mathrm{SD} \pm 47.27$ ) (Fig. 2b, Table 2). However, there was no significant difference $(p=0.940)$ in serum leptin levels between ccRCC (median, $4039.31 \mathrm{pg} / \mathrm{ml}$; SD \pm 2319.33) and non-ccRCC patients (median, 3883.26 $\mathrm{pg} / \mathrm{ml}$; SD \pm 2312.54 ) (Fig 2c, Table 2).

Table 1. Patient demographic and clinical characteristics.

\begin{tabular}{|c|c|c|c|}
\hline Characteristics & RCC patients & Normal controls & $P$ value \\
\hline Gender, N (\%) & & & $0.888^{\mathrm{a}}$ \\
\hline Male & $140(70.7)$ & $60(69.8)$ & \\
\hline Female & $58(29.3)$ & $26(30.2)$ & \\
\hline \multicolumn{4}{|l|}{ Median (range) } \\
\hline Age, years & $54.00(22-76)$ & $56.00(23-74)$ & $0.197 \mathrm{~b}$ \\
\hline BMI, $\mathrm{kg} / \mathrm{m}^{2}$ & $24.22(16.89-35.91)$ & $24.06(17.14-29.76)$ & $0.840^{\mathrm{b}}$ \\
\hline VFA, $\mathrm{cm}^{2}$ & $104.82(12.39-203.20)$ & - & \\
\hline SFA, $\mathrm{cm}^{2}$ & $123.27(26.36-320.28)$ & - & \\
\hline $\mathrm{TFA}, \mathrm{cm}^{2}$ & $243.33(50.30-468.77)$ & - & \\
\hline VFA $\%, \%$ & 43.30 (18.20-66.73) & - & \\
\hline Adiponectin, ug $/ \mathrm{ml}$ & $6.33(1.01-20.70)$ & $9.54(4.81-25.32)$ & $<0.001^{c}$ \\
\hline Leptin, $\mathrm{pg} / \mathrm{ml}$ & $\begin{array}{l}4009.87 \\
(144.39-10468.08)\end{array}$ & $\begin{array}{l}5416.79 \\
(498.35-13194.02)\end{array}$ & $<0.001^{b}$ \\
\hline \multicolumn{4}{|l|}{ N (\%) } \\
\hline Hypertension & $64(32.3)$ & $24(27.9)$ & $0.488^{a}$ \\
\hline Diabetes & $22(11.1)$ & $6(7.0)$ & $0.387 \mathrm{a}$ \\
\hline Smoking status & $78(39.4)$ & $27(31.4)$ & $0.229 a$ \\
\hline \multicolumn{4}{|l|}{ Malignant pathology } \\
\hline Clear cell & $156(78.8)$ & - & \\
\hline Papillary & $4(2.0)$ & - & \\
\hline Chromophobe & $28(14.1)$ & - & \\
\hline Unclassified & $10(5.1)$ & - & \\
\hline
\end{tabular}

a: $p$-value derived from Fisher's exact test; b: $p$-value derived from Student's $\mathrm{t}$ test; c: $p$-value derived from Mann-Whitney $\mathrm{U}$ test.

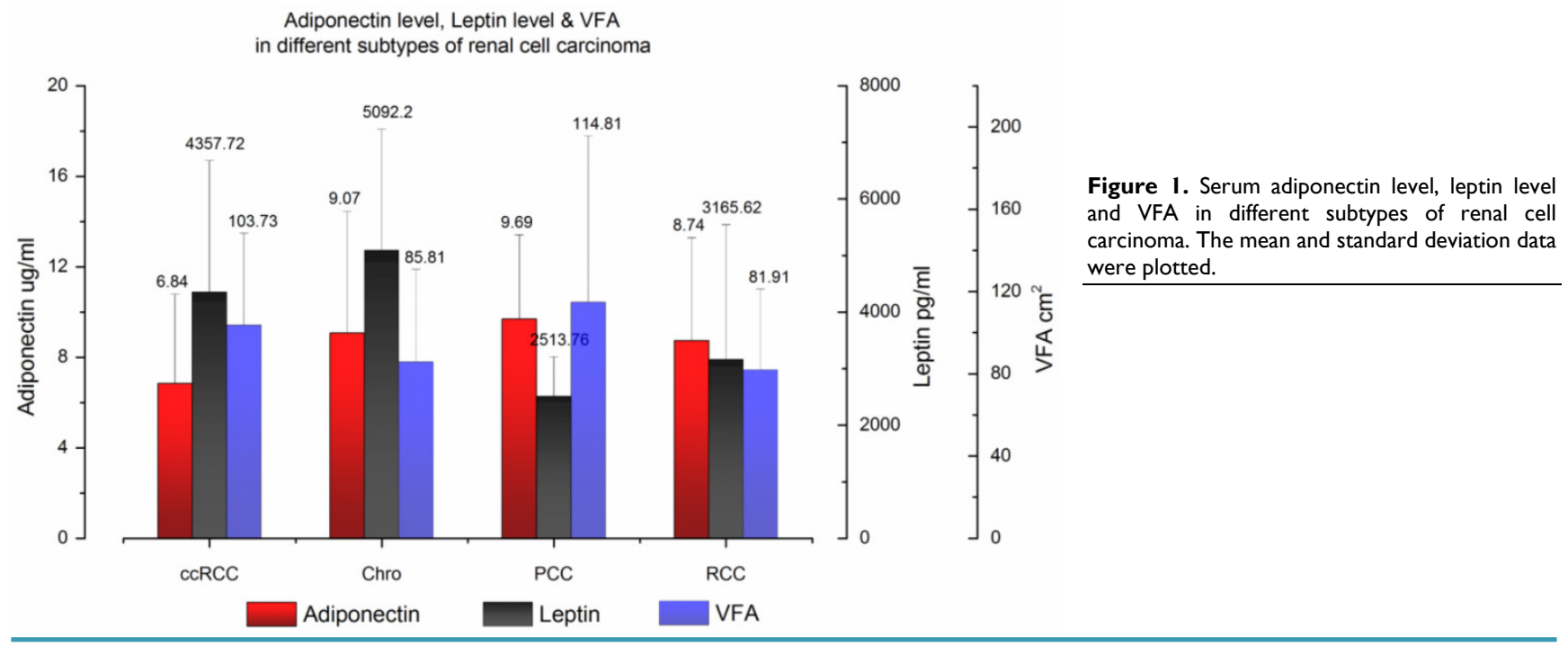



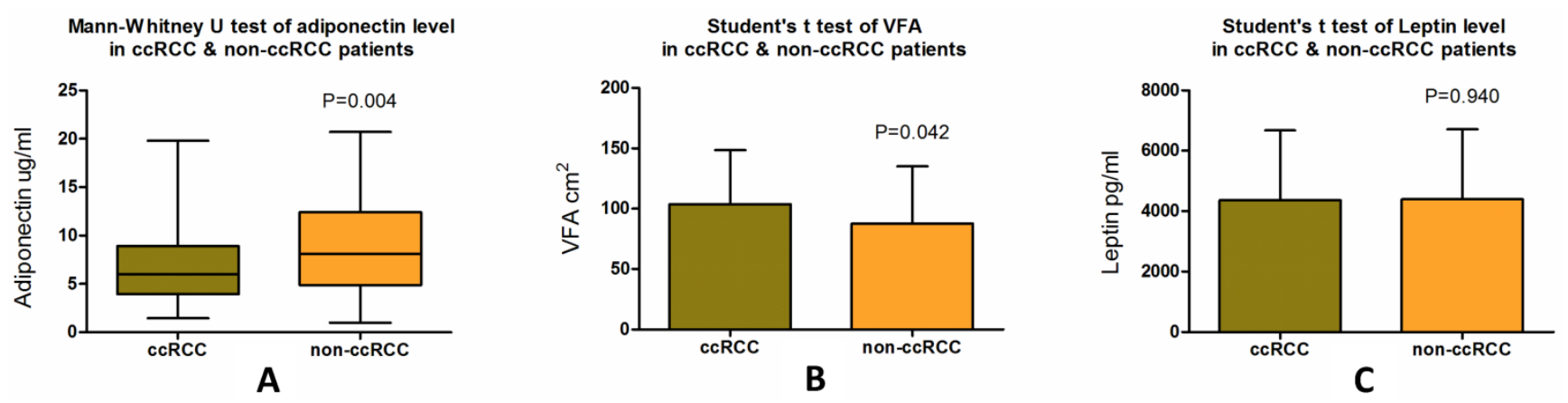

Figure 2. Mann-Whitney $U$ test of serum adiponectin level, Student's $t$ test of VFA and serum leptin level in patients with ccRCC and non-ccRCC. Patients with ccRCC have a significantly lower plasma adiponectin level $(p=0.004)$ and higher VFA $(p=0.044)$ than non-ccRCC patients, while no differences are seen in mean plasma leptin level $(p=0.940)$.
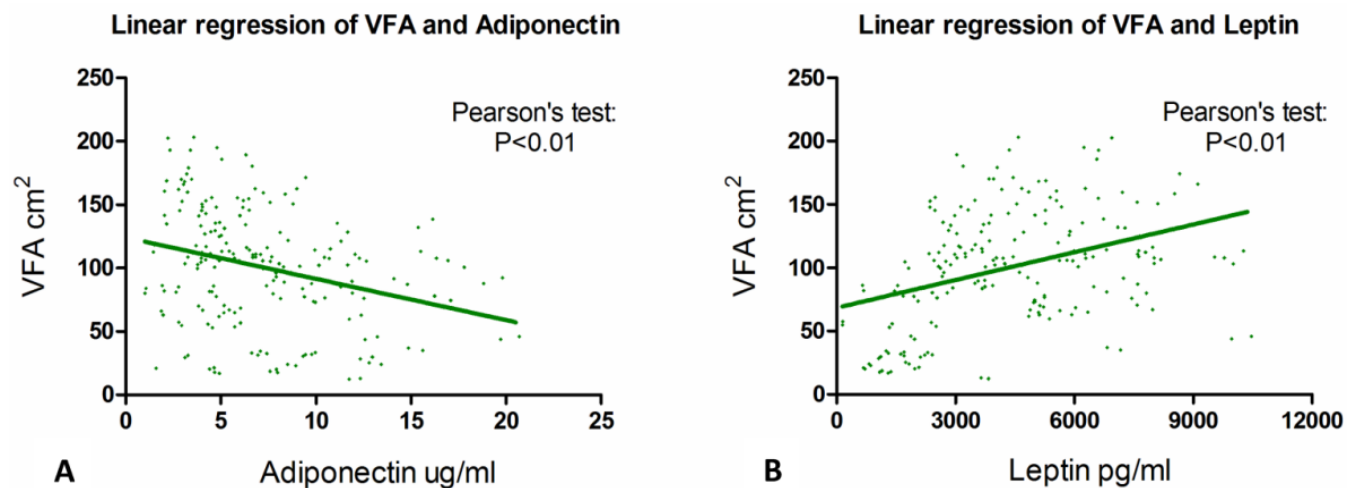

Figure 3. The association of VFA with serum adiponectin and leptin level. Pearson's tests show that the correlation between VFA and serum adiponectin level ( $<<$ $0.001)$ and the link between VFA and serum leptin concentration $(p<0.001)$ are statistically significant.

Table 2. Differences of serum adiponectin, leptin level and VFA between ccRCC patients and non-ccRCC patients.

\begin{tabular}{|c|c|c|c|c|c|c|c|c|c|c|c|c|}
\hline \multirow[t]{2}{*}{ Pathology } & \multicolumn{4}{|c|}{ Serum adiponectin level, $\mathrm{ug} / \mathrm{ml}$} & \multicolumn{4}{|c|}{ Serum leptin level, pg/ml } & \multicolumn{4}{|c|}{ VFA, $\mathrm{cm}^{2}$} \\
\hline & Mean & Median & SD & $P$ & Mean & Median & SD & $P$ & Mean & Median & SD & $P$ \\
\hline ccRCC & 6.84 & 6.01 & 3.94 & 0.004 & 4357.72 & 4039.31 & 2319.33 & 0.940 & 103.73 & 107.79 & 44.63 & 0.042 \\
\hline Non-ccRCC & 9.05 & 8.11 & 4.97 & & 4387.93 & 3883.26 & 2312.54 & & 87.64 & 78.85 & 47.27 & \\
\hline
\end{tabular}

We then performed linear correlation analysis to determine if serum adiponectin or leptin concentration had some linear linkage with VFA. Results from Pearson's tests showed that the correlation between VFA and serum adiponectin level $(p<0.001)$ and between VFA and serum leptin concentration $(p<0.001)$ were both statistically significant (Fig. 3a \& 3b).

We used univariate and multivariate logistic regression analysis to identify predictors that had the potential to differentiate ccRCC from non-ccRCC patients. The regression results are shown in Table 3. We used the pathological characteristics (ccRCC or non-ccRCC) as a binary dependent variable. In univariate analysis, female sex (OR $=0.460,95 \%$ CI $0.226-0.934, \mathrm{p}=0.032)$, greater VFA (OR $=0.992,95 \%$ CI 0.984-1.000, $\mathrm{p}=0.044$ ) and lower serum adiponectin level $(\mathrm{OR}=1.120,95 \%$ CI 1.037-1.209, $\mathrm{p}=$ 0.004 ) were considered to be significant factors in predicting ccRCC. We used the following factors in our multivariate regression analysis: age, BMI, VFA, adiponectin level, leptin level, sex, smoking status, hypertension and diabetes. The first five factors were viewed as continuous variables while the last four factors were considered binary variables. Our results showed that only serum adiponectin level $(\mathrm{OR}=$ 1.120, 95\% CI 1.037-1.209, p $=0.004$ ) was an independent predictor for ccRCC.

We observed that men with ccRCC had lower leptin $(p<0.001)$ and adiponectin $(p=0.002)$ levels than women (Table 4). Obese patients had higher serum leptin levels $(p<0.001)$, and diabetic patients had lower plasma adiponectin levels $(\mathrm{p}=0.001)$ (Table 4). Additionally, patients with greater than 90 $\mathrm{cm}^{2}$ VFA had higher circulating leptin levels, a statistically significant difference $(p<0.001)$. These patients also had lower plasma adiponectin levels $(\mathrm{p}=$ 0.040). However, these two factors had no association with tumor size or Fuhrman grades among ccRCC patients (Table 4). 
Table 3. Univariate analysis and multivariate analysis of predictors for different subtypes of RCC.

\begin{tabular}{|c|c|c|c|c|c|c|}
\hline \multirow[t]{2}{*}{ Characteristics } & \multicolumn{3}{|c|}{ Univariate analysis } & \multicolumn{3}{|c|}{ Multivariate analysis } \\
\hline & $\overline{O R}$ & $95 \% \mathrm{CI}$ & $P$ & OR & $95 \% \mathrm{CI}$ & $P$ \\
\hline Gender (ref.male) & 0.460 & $0.226-0.934$ & 0.032 & 0.627 & $0.279-1.409$ & 0.259 \\
\hline Age (years) & 0.981 & $0.952-1.011$ & 0.209 & 0.979 & $0.948-1.011$ & 0.190 \\
\hline BMI $\left(\mathrm{kg} / \mathrm{m}^{2}\right)$ & 0.904 & 0.806-1.014 & 0.086 & 0.916 & $0.813-1.031$ & 0.146 \\
\hline Smoking statue & 1.833 & $0.874-3.846$ & 0.109 & 1.228 & $0.489-3.079$ & 0.662 \\
\hline Hypertension & 0.943 & $0.457-1.947$ & 0.875 & 0.607 & $0.255-1.444$ & 0.259 \\
\hline Diabetes & 2.941 & $0.659-13.125$ & 0.157 & 1.552 & $0.316-7.628$ & 0.588 \\
\hline $\mathrm{VFA}, \mathrm{cm}^{2}$ & 0.992 & 0.984-1.000 & 0.044 & 1.003 & $0.990-1.017$ & 0.637 \\
\hline Adiponectin (ug/ml) & 1.120 & $1.037-1.209$ & 0.004 & 1.120 & $1.037-1.209$ & 0.004 \\
\hline Leptin (ug/ml) & 1.000 & $1.000-1.000$ & 0.940 & 1.000 & $1.000-1.000$ & 0.625 \\
\hline
\end{tabular}

Table 4. Association between clinical parameters and plasma adiponectin/leptin levels in the ccRCC subgroup.

\begin{tabular}{|c|c|c|c|c|c|c|c|c|c|}
\hline \multirow{2}{*}{$\begin{array}{l}\text { Characteristics } \\
\text { (ccRCC patients) }\end{array}$} & & \multicolumn{4}{|c|}{ Serum adiponectin level, $\mathrm{ug} / \mathrm{ml}$} & \multicolumn{4}{|c|}{ Serum leptin level, ug/ml } \\
\hline & & Mean & Median & SD & $P^{\mathrm{a}}$ & Mean & Median & SD & ${ }^{\mathrm{b}}$ \\
\hline Gender, N (\%) & & & & & 0.002 & & & & $<0.001$ \\
\hline Male & $116(74.4)$ & 6.15 & 5.80 & 3.33 & & 3867.89 & 3668.66 & 2101.24 & \\
\hline Female & $40(25.6)$ & 8.81 & 7.56 & 4.87 & & 5778.23 & 5951.87 & 2361.55 & \\
\hline Fuhrman grading, $\mathrm{N}(\%)$ & & & & & 0.769 & & & & 0.321 \\
\hline I \& II & $89(57.1)$ & 7.05 & 5.73 & 4.50 & & 4518.12 & 4162.68 & 2187.07 & \\
\hline III\&IV & $67(42.9)$ & 6.56 & 6.03 & 3.06 & & 4144.66 & 3842.73 & 2484.91 & \\
\hline Obesity, N (\%) & & & & & 0.787 & & & & $<0.001$ \\
\hline Yes & $38(24.4)$ & 6.97 & 5.57 & 4.55 & & 6357.22 & 6389.28 & 1824.57 & \\
\hline No & $118(75.6)$ & 6.79 & 6.03 & 3.75 & & 3713.82 & 3491.73 & 2087.35 & \\
\hline Tumor size, N (\%) & & & & & 0.069 & & & & 0.461 \\
\hline$\leq 4 \mathrm{~cm}$ & $104(66.7)$ & 6.57 & 5.11 & 4.08 & & 4454.82 & 4241.57 & 2361.11 & \\
\hline$>4 \mathrm{~cm}$ & $52(33.3)$ & 7.38 & 7.09 & 3.62 & & 4163.53 & 3542.64 & 2243.26 & \\
\hline Diabetes, N (\%) & & & & & 0.001 & & & & 0.239 \\
\hline Yes & $20(12.8)$ & 4.31 & 4.22 & 1.75 & & 4929.27 & 5087.72 & 2762.78 & \\
\hline No & $136(87.2)$ & 7.21 & 6.41 & 4.04 & & 4273.67 & 3971.23 & 2246.44 & \\
\hline Hypertension, N (\%) & & & & & 0.362 & & & & 0.263 \\
\hline Yes & $50(32.1)$ & 6.42 & 5.55 & 4.01 & & 4661.06 & 5034.98 & 2339.05 & \\
\hline No & $106(67.9)$ & 7.03 & 6.33 & 3.91 & & 4214.64 & 3797.49 & 2307.21 & \\
\hline VFA, N (\%) & & & & & 0.040 & & & & $<0.001$ \\
\hline$<90 \mathrm{~cm}^{2}$ & $55(35.3)$ & 7.75 & 7.42 & 4.24 & & 2998.96 & 2217.54 & 2141.43 & \\
\hline$\geq 90 \mathrm{~cm}^{2}$ & $101(64.7)$ & 6.34 & 5.44 & 3.70 & & 5097.64 & 4583.48 & 2072.02 & \\
\hline
\end{tabular}

a. Mann-Whitney U test. b. Student's t test.

\section{Discussion}

In this study, we demonstrated that a lower plasma adiponectin level may be a predictor for differentiating ccRCC from non-ccRCC. We showed that compared with other types of RCC, cCRCC patients have a lower plasma adiponectin level and greater VFA (Fig. 2a \& Fig. 2b). We also found a clear inverse linear correlation between VFA and plasma adiponectin concentration. Furthermore, among patients with ccRCC, we observed a significantly higher leptin level in obese people. In the ccRCC subgroup, we also found that people with diabetes had a lower plasma adiponectin level. For ccRCC patients with a VFA $\geq 90 \mathrm{~cm}^{2}$, we observed a significantly higher leptin level and a lower adiponectin level. Neither plasma adiponectin nor leptin levels were significantly correlated with tumor size or Fuhrman grade in ccRCC patients.

It has been previously noted that obesity is associated with RCC. In one study it was reported that obesity could increase the risk of RCC in both men and women by up to 1.7 -fold and 4.75 -fold, respectively [14]. In a recent meta-analysis, similar results were reported [15]. Other research groups suggested that obesity, defined as a high BMI, was an independent predictor for ccRCC in patients with a renal cortical tumor $[16,17]$. Equally important, some researchers found that BMI could help differentiate ccRCC from non-ccRCC [16]. However, BMI represents the overall condition of a patient, while visceral fat is involved in the biological functions. It is believed that visceral obesity is strongly associated with an increased risk of insulin resistance, metabolic syndrome and cardiovascular disease, independently from BMI [18]. Therefore, focusing on VFA and its associated adipokines is a better choice for understanding the link between obesity and the origin of RCC. In our previous study, we found that VFA was associated with different pathological subtypes of RCC [5] and that there are significant relationships 
between the percentage of visceral adipose tissue and both tumor size and higher Fuhrman grades [19]. The results of the current study are an extension of our previous findings.

So far, no direct mechanism defining how VFA alters the pathophysiology of RCC has been discovered, what we know is that VFA decreases the expression of adiponectin, a well-known metabolically active polypeptide [20]. Researches have revealed that adiponectin has insulinsensitizing, anti-inflammatory, antiatherosclerotic and anticancer properties [21]. An inverse correlation between circulating adiponectin level and the incidence of RCC has been observed [13] and a low concentration of adiponectin is significantly associated with a larger tumor size and a risk of metastasis, particularly in ccRCC [7].

However, it has been unclear if the circulating adiponectin level could be used to discriminate ccRCC from non-ccRCC. In this study, we focused on that question and demonstrated that ccRCC patients have a relatively lower plasma adiponectin concentration than patients with papillary RCC, chromophobe RCC and unclassified RCC, and that for every $1 \mu \mathrm{g} / \mathrm{ml}$ decrease in serum adiponectin level, there is a $12 \%$ increase in the probability of having ccRCC.

Different subtypes of RCC have a diverse pathology, genetics and biology. For example, ccRCC is known for its epigenetic silencing of the VHL gene and an HIF pathway alteration. Abnormal MET or the $F H$ gene may be seen in papillary RCC and chromophobe RCC may be associated with changes in the BHD or FLCN genes [22]. This may explain why some researchers have found different lipid profiles between ccRCC and non-ccRCC [23, 24]. It is also possible that the tumors themselves have the ability to secrete cytokines. Schips et al. showed that insulin-like growth factor was expressed differentially among different tumor types, and it was detected in $110(82.1 \%)$ of 134 clear cell, eight $(36 \%)$ of 22 chromophobe, and three (15\%) of 20 papillary RCCs $(P<0.001)$ [25]. In another study, the authors found that transforming growth factor (TGF)-alpha and fibroblast growth factor (FGF) also have different secretion rates in different RCC subtypes [26]. It is also possible that sometimes the expression of adiponectin in adipose tissues is tumor guided, considering that inflammatory conditions may affect gene expression and the function of human adipose tissue-derived mesenchymal stem cells [27]. Conversely, results from a genome-wide association study (GWAS) identified an rs718314 in inositol 1, 4, 5-triphosphate receptor, type 2 (ITPR2) gene which is both associated with RCC cancer risk and
Waist-to-Hip Ratio, reminding us that obesity and RCC may have a parallel cause [28]. Additionally, our research group previously reported that a single nucleotide polymorphism (rs182052) in the adiponectin gene is significantly associated with ccRCC risk [28], indicating that patients with ccRCC may have distinctive adipose metabolic characteristics due to special genetic backgrounds.

It is interesting that VFA achieved statistical significance in univariate analysis for predicting ccRCC, but the effect diminished in multivariate analysis. Taking the following two results into consideration, we believe that the effect of VFA in differentiating ccRCC from other subtypes might be partly attributed to adiponectin levels. One finding was that plasma adiponectin levels outweighed other factors in the multivariate analysis for predicting ccRCC. The other finding was that we confirmed a clear inverse linear correlation between circulating adiponectin levels and VFA. In the past, some studies have shown different effects of serum leptin levels in RCC $[9,10,29]$. In our study, we tested serum leptin levels but did not find any clear correlation either in our entire cohort or in the ccRCC patients only.

The limitations of our study include its retrospective nature without control groups and a relatively small size of 198 patients. There is a certain selection bias because we only recruited patients from our hospital, a single cancer center. In addition, we excluded metastatic cancer patients because cachexia has a significant influence on VFA values. We also excluded patients with extreme plasma adiponectin/leptin concentrations and patients with benign tumors. In addition, we only tested plasma adiponectin and leptin concentrations. As other authors have pointed out, there are many other adipokines released or affected by adipose tissues, such as interleukin-6 (IL-6) [30], plasminogen-activator inhibitor type I (PAI-I) [31], and adipsin [32]. However, adiponectin and leptin receptors on cancer cells are also important factors related to adipokine serum concentrations $[33,34]$. We have initiated an analysis of other cytokines and receptors in RCC patients. Furthermore, basic medical research will be necessary to clarify the mechanism of adiponectin in ccRCC carcinogenesis. Finally, all of the patients recruited in our study are Chinese, so the results of our study may need to be verified in other ethnic populations.

\section{Conclusion}

This is the first study to identify an association between serum adiponectin level and different histological types of RCC. Lower plasma adiponectin concentrations are related to an increased incidence of 
ccRCC and may act as an independent predictor for ccRCC. Our study may help define the chain from obesity to adipose tissue, to cytokines and finally to ccRCC.

\section{Abbreviations}

RCC: renal cell carcinoma; ccRCC: clear cell renal
cell $\quad$ carcinoma; $\quad$ ELISA: enzyme-linked immunosorbent assay; BMI: body mass index; VFA: visceral fat accumulation; TFA: total fat accumulation; SFA: subcutaneous fat accumulation; WAT: white adipose tissue; TNF-a: tumor necrosis factor-a; IL-6: interleukin-6; AdipoR1: adiponectin receptor 1

\section{Acknowledgement}

This work was supported by Project 81001131 supported by the National Natural Science Foundation of China and Project 16QA1401100 supported by the Shanghai Rising Star Program.

\section{Authors' contribution}

Author contributions: Hongkai Wang, Junlong $\mathrm{Wu}$ and Yao Zhu had full access to all of the data in the study and take responsibility for the integrity of the data and the accuracy of the data analysis. Acquisition of data: Hong-Kai Wang, Junlong $\mathrm{Wu}$, Weijie $\mathrm{Gu}$, and Yao Zhu. Study concept and design: Hongkai Wang and Yao Zhu. Manuscript writing: Hongkai Wang and Junlong Wu. Statistical analysis: Junlong $\mathrm{Wu}$, Beihe Wang, Fangnin Wan. Revision of the manuscript for intellectual content: Bo Dai, Hailiang Zhang, Yi-Jun Shen, Guo-Hai Shi, Yi-Ping Zhu. Correspondence: Ding-Wei Ye and Yao Zhu.

\section{Competing Interests}

The authors declare that they have no competing financial interests.

\section{References}

1. Siegel RL, Miller KD, Jemal A. Cancer statistics, 2015. CA: a cancer journal for clinicians. 2015; 65: 5-29.

2. Flegal KM, Graubard BI, Williamson DF, Gail MH. Cause-specific excess deaths associated with underweight, overweight, and obesity. Jama. 2007; 298: 2028-37.

3. Renehan AG, Tyson M, Egger M, Heller RF, Zwahlen M. Body-mass index and incidence of cancer: a systematic review and meta-analysis of prospective observational studies. Lancet (London, England). 2008; 371: 569-78.

4. Choi Y, Park B, Jeong BC, Seo SI, Jeon SS, Choi HY, et al. Body mass index and survival in patients with renal cell carcinoma: a clinical-based cohort and meta-analysis. International journal of cancer Journal international du cancer. 2013; 132: 625-34.

5. Wang H-K, Song X-S, Cheng Y, Qu Y-Y, Zhang S-L, Dai B, et al. Visceral fat accumulation is associated with different pathological subtypes of renal cell carcinoma (RCC): a multicentre study in China. BJU International. 2014; 114: 496-502.

6. Arita Y, Kihara S, Ouchi N, Takahashi M, Maeda K, Miyagawa J, et al. Paradoxical decrease of an adipose-specific protein, adiponectin, in obesity. Biochemical and biophysical research communications. 1999; 257: 79-83.

7. Pinthus JH, Kleinmann N, Tisdale B, Chatterjee S, Lu JP, Gillis A, et al. Lower plasma adiponectin levels are associated with larger tumor size and metastasis in clear-cell carcinoma of the kidney. European urology. 2008; 54: 866-73.

8. Chou SH, Tseleni-Balafouta S, Moon HS, Chamberland JP, Liu X, Kavantzas $\mathrm{N}$, et al. Adiponectin receptor expression in human malignant tissues. Hormones \& cancer. 2010; 1: 136-45.
9. Spyridopoulos TN, Petridou ET, Dessypris N, Terzidis A, Skalkidou A, Deliveliotis C, et al. Inverse association of leptin levels with renal cell carcinoma: results from a case-control study. Hormones (Athens, Greece). 2009; 8: 39-46.

10. Liao LM, Schwartz K, Pollak M, Graubard BI, Li Z, Ruterbusch J, et al. Serum leptin and adiponectin levels and risk of renal cell carcinoma. Obesity (Silver Spring, Md). 2013; 21: 1478-85.

11. Lopez-Beltran A, Scarpelli M, Montironi R, Kirkali Z. 2004 WHO classification of the renal tumors of the adults. European urology. 2006; 49: 798-805.

12. Goh VH, Tain CF, Tong TY, Mok HP, Wong MT. Are BMI and other anthropometric measures appropriate as indices for obesity? A study in an Asian population. Journal of lipid research. 2004; 45: 1892-8.

13. Spyridopoulos TN, Petridou ET, Skalkidou A, Dessypris N, Chrousos GP, Mantzoros CS. Low adiponectin levels are associated with renal cell carcinoma: a case-control study. International journal of cancer Journal international du cancer. 2007; 120: 1573-8.

14. Calle EE, Rodriguez C, Walker-Thurmond K, Thun MJ. Overweight, obesity, and mortality from cancer in a prospectively studied cohort of U.S. adults. The New England journal of medicine. 2003; 348: 1625-38.

15. Wang $\mathrm{F}, \mathrm{Xu}$ Y. Body mass index and risk of renal cell cancer: a dose-response meta-analysis of published cohort studies. International journal of cancer Journal international du cancer. 2014; 135: 1673-86.

16. Lowrance WT, Thompson RH, Yee DS, Kaag M, Donat SM, Russo P. Obesity is associated with a higher risk of clear-cell renal cell carcinoma than with other histologies. BJU Int. 2010; 105: 16-20.

17. Donat SM, Salzhauer EW, Mitra N, Yanke BV, Snyder ME, Russo P. Impact of body mass index on survival of patients with surgically treated renal cell carcinoma. The Journal of urology. 2006; 175: 46-52.

18. Ibrahim MM. Subcutaneous and visceral adipose tissue: structural and functional differences. Obes Rev. 2010; 11: 11-8.

19. Zhu Y, Wang HK, Zhang HL, Yao XD, Zhang SL, Dai B, et al. Visceral obesity and risk of high grade disease in clinical t1a renal cell carcinoma. The Journal of urology. 2013; 189: 447-53.

20. Chandran M, Phillips SA, Ciaraldi T, Henry RR. Adiponectin: more than just another fat cell hormone? Diabetes care. 2003; 26: 2442-50.

21. Brochu-Gaudreau K, Rehfeldt C, Blouin R, Bordignon V, Murphy BD, Palin MF. Adiponectin action from head to toe. Endocrine. 2010; 37: 11-32.

22. Shuch B, Amin A, Armstrong AJ, Eble JN, Ficarra V, Lopez-Beltran A, et al. Understanding pathologic variants of renal cell carcinoma: distilling therapeutic opportunities from biologic complexity. Eur Urol. 2015; 67: 85-97.

23. Tugnoli V, Trinchero A, Tosi MR. Evaluation of the lipid composition of human healthy and neoplastic renal tissues. The Italian journal of biochemistry. 2004; 53: 169-82.

24. Righi V, Mucci A, Schenetti L, Tosi MR, Grigioni WF, Corti B, et al. Ex vivo HR-MAS magnetic resonance spectroscopy of normal and malignant human renal tissues. Anticancer research. 2007; 27: 3195-204

25. Schips L, Zigeuner R, Ratschek M, Rehak P, Ruschoff J, Langner C. Analysis of insulin-like growth factors and insulin-like growth factor I receptor expression in renal cell carcinoma. Am J Clin Pathol. 2004; 122: 931-7.

26. Ramp U, Reinecke P, Gabbert HE, Gerharz CD. Differential response to transforming growth factor (TGF)-alpha and fibroblast growth factor (FGF) in human renal cell carcinomas of the clear cell and papillary types. Eur J Cancer. 2000; 36: 932-41.

27. Crop MJ, Baan CC, Korevaar SS, Ijzermans JN, Pescatori M, Stubbs AP, et al. Inflammatory conditions affect gene expression and function of human adipose tissue-derived mesenchymal stem cells. Clin Exp Immunol. 2010; 162: 474-86.

28. Zhang G, Gu C, Zhu Y, Luo L, Dong D, Wan F, et al. ADIPOQ polymorphism rs182052 is associated with clear cell renal cell carcinoma. Cancer science 2015 . 106: 687-91.

29. Horiguchi A, Sumitomo M, Asakuma J, Asano T, Zheng R, Asano T, et al. Increased serum leptin levels and over expression of leptin receptors are associated with the invasion and progression of renal cell carcinoma. The Journal of urology. 2006; 176: 1631-5.

30. Bastard JP, Maachi M, Van Nhieu JT, Jardel C, Bruckert E, Grimaldi A, et al. Adipose tissue IL- 6 content correlates with resistance to insulin activation of glucose uptake both in vivo and in vitro. The Journal of clinical endocrinology and metabolism. 2002; 87: 2084-9.

31. Shimomura I, Funahashi T, Takahashi M, Maeda K, Kotani K, Nakamura T, et al. Enhanced expression of PAI-1 in visceral fat: possible contributor to vascular disease in obesity. Nature medicine. 1996; 2: 800-3.

32. White RT, Damm D, Hancock N, Rosen BS, Lowell BB, Usher P, et al. Human adipsin is identical to complement factor $\mathrm{D}$ and is expressed at high levels in adipose tissue. The Journal of biological chemistry. 1992; 267: 9210-3.

33. Punyadeera C, Zorenc AH, Koopman R, McAinch AJ, Smit E, Manders R, et al. The effects of exercise and adipose tissue lipolysis on plasma adiponectin concentration and adiponectin receptor expression in human skeletal muscle. European journal of endocrinology / European Federation of Endocrine Societies. 2005; 152: 427-36.

34. Kielar D, Clark JS, Ciechanowicz A, Kurzawski G, Sulikowski T, Naruszewicz M. Leptin receptor isoforms expressed in human adipose tissue. Metabolism: clinical and experimental. 1998; 47: 844-7. 